\title{
Health-related quality of life in adults reporting arthritis: analysis from the National Health Measurement Study
}

\author{
Dinesh Khanna - Paul Maranian - Mari Palta • \\ Robert M. Kaplan • Ron D. Hays • Dasha Cherepanov • \\ Dennis G. Fryback
}

Accepted: 13 January 2011/Published online: 5 February 2011

(C) The Author(s) 2011. This article is published with open access at Springerlink.com

\begin{abstract}
Background Arthritis is the leading cause of disability in the United States. We assess the generic health-related quality-of-life (HRQOL) among a nationally representative sample of US adults with and without self-reported arthritis.

Methods The NHMS, a cross-sectional survey of 3,844 adults (35-89 years) administered EuroQol-5D (EQ-5D), Health Utilities Index Mark 2 (HUI2) and 3 (HUI3), SF36v2 $2^{\mathrm{TM}}$, Quality of Well-being Scale self-administered form (QWB-SA), and the Health and Activities Limitations index (HALex) to each respondent via a telephone
\end{abstract}

D. Khanna $(\bowtie) \cdot$ P. Maranian

Division of Rheumatology, Department of Medicine, David Geffen School of Medicine, University of California at Los Angeles, 1000 Veteran Avenue, Rm 32-59 Rehabilitation

Building, Los Angeles, CA 90095, USA

e-mail: dkhanna@mednet.ucla.edu

R. M. Kaplan · R. D. Hays

Department of Medicine, David Geffen School of Medicine,

University of California at Los Angeles, Los Angeles, CA, USA

D. Khanna · R. M. Kaplan · R. D. Hays · D. Cherepanov Department of Health Services, School of Public Health, University of California at Los Angeles, Los Angeles, CA 90095, USA

M. Palta · D. G. Fryback

Department of Population Health Sciences, University

of Wisconsin-Madison, Madison, WI, USA

M. Palta

Department of Biostatistics and Medical Informatics, University of Wisconsin-Madison, Madison, WI, USA

D. G. Fryback

Department Industrial and Systems Engineering, University of Wisconsin-Madison, Madison, WI, USA interview. Weighted multiple linear regression was used to generate age-gender-arthritis-stratified unadjusted HRQOL means and means adjusted for sociodemographic, socioeconomic covariates and comorbidities by arthritis-age category.

Results The estimated population prevalence of selfreported arthritis was $31 \%$. People with arthritis were more likely to be woman, older, of lower socioeconomic status, and had more self-reported comorbidities than were those not reporting arthritis. Adults with arthritis had lower HRQOL on six different indexes compared with adults without arthritis, with overall differences ranging from 0.03 (QWB-SA, age-group 65-74) to 0.17 (HUI3, agegroup 35-44; all $P$-value $<.05$ ).

Conclusion Arthritis in adults is associated with poorer HRQOL. We provide age-related reference values for six generic HRQOL measures in people with arthritis.

Keywords Health-Related Quality of Life - HRQOL . Arthritis · National Health Measurement Study ·

Self-reported arthritis · EQ-5D · SF-6D · HUI2 - HUI3 · HALex · QWB · QWB-SA

\section{Introduction}

Arthritis affects approximately 46.4 million people in United States (US) [1], is the leading cause of physical disability, and has a detrimental effect on health-related quality of life (HRQOL) [2]. Measuring and monitoring population HRQOL can help guide public policy by identifying vulnerable populations, tracking population trends, and assessing the impact of established policies on HRQOL relative to established national averages [3]. HRQOL measures summarize multiple dimensions of health into a 
single score, and several measures are available to capture the physical, mental, and social dimensions of health [4]. Disease-specific measures for arthritis such as the Arthritis Impact Measurement Scales (AIMS) [5, 6] or the Health Assessment Questionnaire (HAQ) [7] ask patients about selected activities and experiences that are generally assumed to be affected by the disease. Generic HRQOL indexes are not targeted to a specific disease experience, but instead attempt to summarize function and well-being across a comprehensive set of domains that are conceptualized to underpin health as experienced by an individual. Preference-based generic indexes are scored by summarizing across health domains using so-called preference weights, systematically collected from a general population sample of adults. These utility-based measures summarize multiple domains and place overall wellness on a continuum ranging from 0.0 (health state of dead) to 1.0 (health state of perfect or full health) using measure-specific community preference-weighted scoring functions. These measures can be used to adjust survival time for quality of life and are designed to yield quality-adjusted life years (QALYs) that can be used in cost-effectiveness analysis.

Population-level HRQOL data have been reported for several chronic diseases, including arthritis [2, 8-22]. Ko and Coons reported US-based EuroQol-5D (EQ-5D) scores for chronic conditions (including arthritis) from the US population and reported relative HRQOL decrements associated with various chronic conditions [22]. Anderson and colleagues assessed decrements in Quality of WellBeing (QWB) associated with self-reported arthritis in the National Health Interview Survey (NHIS) data [15]. Mo and colleagues analyzed Health utilities Index (HUI) in the Canadian Community Health Survey (CCHS) for 2000-2001 and reported that arthritis/rheumatism has a severe impact on HRQOL [19]. However, no study has directly compared commonly used HRQOL measures in a population-based survey in United States.

The present study assesses the impact of self-reported arthritis in the US adult population using six widely used generic indexes and provides reference HRQOL values for these measures in people with arthritis.

\section{Materials and methods}

We utilized data from the National Health Measurement Study (NHMS) [23] - a national cross-sectional sample of adults in United States where EuroQol-5D (EQ-5D) [24], Health Utilities Index Mark 2 (HUI2) [25], Health Utilities Index Mark 3 (HUI3) [26], SF-6D (a summary index derived from the SF-36v2 $2^{\mathrm{TM}}$ questionnaire) [27], Quality of Well-being Scale self-administered form (QWB-SA) [28], and the Health and Activities Limitations index
(HALex) [29] were all administered via a telephone interview to each respondent.

NHMS was a random digit-dialed (RDD) telephone interview of a sample of 3,844 adults aged 35-89 years, designed to represent the older half of the non-institutionalized US population in 2000 (median age was 36.4 years, http://factfinder.census.gov) from the continental United States [23]. People aged 65-89, and telephone exchanges with high percentages of African Americans were oversampled. When a household with at least one resident aged 35-89 was contacted, one of the three age ranges (35-44, $45-64,65+)$ was sampled using pre-specified weights favoring older ages to determine who if anyone would be interviewed. If there were more than one person in the selected age range, the Troldahl-Carter-Bryant method [30] was used to select a respondent. At most one person was selected per household. Each respondent completed the six HRQOL instruments. Our case definition of arthritis was based on self-reported arthritis [1, 31]: "Have you ever been told (by a doctor or other health professional) that you had arthritis?" This definition is thought to provide credible overall arthritis surveillance with acceptable sensitivity and specificity $[32,33]$ and has been used in other population surveys $[1,31]$.

\section{HRQOL instruments}

The six HRQOL indexes are described in Fryback et al. [23]. Briefly, the EQ-5D, which we computed using US weights [34], is a five-question index asking about mobility, self-care, restrictions of usual activities, pain/discomfort and anxiety/depression. The SF-6D [27] is constructed using 11 of 36 questions from the widely used SF-36v2 $2^{\mathrm{TM}}$ [35]. The SF-6D uses questions concerning physical function, limitations in role functioning, social function, pain, mental health, and vitality. The HUI2 [25] and HUI3 [26] are related measures computed from the Health Utilities Index questionnaire. The HUI2 defines health status on six domains (sensation, mobility, emotion, cognition, self-care, and pain-we excluded an optional fertility dimension). HUI3 addresses vision, hearing, speech, ambulation, dexterity, emotion, cognition, and pain. The QWB-SA summarizes functioning and mobility, physical activity, and social activity, but also collects extensive information about 58 symptoms/problem complexes. The four domains into a single score QWB-SA [28]. Finally, the HALex [29] is an index-constructed post hoc to use data collected by the recurring NHIS. HALex combines level of physical activity restriction with self-rated health (excellent, very good, good, fair, poor) and derives single weighted score using preferences from the HUI.

Three indexes, EQ-5D, HUI2, and HUI3 allow scores less than 0.0 to reflect health states considered worse than 
dead by the general population samples from which those indexes' weighting schemes were derived.

\section{Statistical analysis}

To allow analyses to reflect the target US population, observations in the NHMS data set are supplied with survey weights computed first as the inverse sampling probability for each participant based on the sampling scheme and then post-stratified to the US Census 2000 population by age, gender, and race [23]. Descriptive statistics (Table 1) and mean estimates of the six HRQOL indexes (Table 2, Fig. 1, "Appendix") incorporated these weights using the "svyset" collection of commands available in STATA10.2 (Stata Corp., College Station, TX).

Unadjusted estimates of the six HRQOL indexes, stratified by age, gender, and arthritis category, were computed as the survey-weighted mean and standard error (SE) of the index for each age/gender/arthritis combination (Table 2). Age-groups were defined as 35-44, 45-54, 55-64, 65-74, and 75-89. Estimates stratified by age-group and arthritis category were then recomputed adjusting for demographic variables and comorbidities selected based on Table 1 (see Fig. 1, "Appendix"). Under this approach, the HRQOL index is modeled as a continuous variable using surveyweighted linear regression. Predictors in the model consist of dummy variables for age-group and arthritis category, the interaction of age-group and arthritis category, and the following: gender, race (White, African American, Other), level of education (less than high school, high school, some post-high school, 4-year college degree or higher), household income $(<\$ 20,000, \$ 20,000-\$ 34,999, \quad \$ 35,000-$ $\$ 74,999,>\$ 75,000)$, body mass index (BMI) as a continuous variable, and the presence or absence of the following self-reported health care professional-diagnosed comorbidities: coronary heart disease, diabetes, stroke, COPD, and sleeping disorder. We did not adjust for depression as mental health is represented in each of $6 \mathrm{HRQOL}$ indexes. The following covariates were centered to the US Census 2000 population proportions where possible and to survey means and proportions from NHMS when census data were not available (centering values provided in parentheses): male gender (0.474), BMI (27.6), history of coronary heart disease (0.092), history of stroke (0.039), diabetes (0.122), COPD (0.131), and sleeping disorder (0.080). For $k$-level categorical variables, $k-1$ indicator variables each centered to the population or survey proportion for the appropriate level were incorporated into the model as follows: race (African American: 0.105, other race: 0.086), education (high school: 0.286, some post-high school: 0.273 , 4-year college degree or higher: 0.244), and income level (\$20,000-\$34,999: 0.183, \$35,000-\$74,999: 0.353 , $\$ 75,000+$ : 0.249 ). Estimates of HRQOL mean and SE of the mean for each age-group/arthritis category were found by applying the appropriate post-estimation linear contrast involving the intercept term, dummy variables for agegroup and arthritis category, and age-group-by-arthritis interaction terms.

\section{Results}

Briefly, NHMS showed 3,844 adults aged 35-89 were reached by random digit telephone sampling, representing an estimated response rate of $56 \%$ between June 2005 and August 2006. The unweighted sample constituted of $57.3 \%$ women, 44\% aged 65-89, and 28\% African American (Table 1) [23]. The rough estimate for response rates (based on comparing the age distribution weighted by inverse sampling probability with that weighted by poststratification weights) was as follows: $39 \%$ for age 35-44 years, 67\% for age 45-54 years, 69\% for age 55-64 years, 55\% for age 65-74 years, and 59\% for age 75-89 years. The six indexes generally showed similar patterns of decrease with mean scores.

In the present analysis, the estimated population prevalence of self-reported arthritis in the 35-89 age range of non-institutionalized individuals was $31 \%$, or 44.2 million adults among the 141.2 million US adults represented by NHMS in the Census 2000 population. Similar prevalence estimates were found in other large national surveys in the United States (Table 3). People with arthritis were more likely to be women, older, of lower socioeconomic status, and had more self-reported comorbidities (Table 1) than were those not reporting arthritis.

Adults with arthritis had lower mean HRQOL than adults without arthritis in all gender by age-groups for each of the six HRQOL indexes (Table 2). The EQ-5D means were highest for each age stratum; HUI2, HUI3, SF-6D, and HALex means were in the mid-range; and QWB-SA were the lowest for the arthritis and non-arthritis groups. Women with arthritis had lower mean HRQOL indexes in the 55-89 agegroups (except for HUI2 where women and men had the same mean score of 0.68 for the 55-64 age-group). Women and men without arthritis had similar mean HRQOL scores for all 6 indexes when stratified by age-groups.

Results of the adjusted analyses are shown graphically in the Fig. 1 (and "Appendix"). Each subpanel corresponds to an HRQOL index and the estimated HRQOL mean across the age-groups is presented separately for patients with and without arthritis. Error bars correspond to $95 \%$ confidence intervals based on the standard errors estimated from the models. Tests of the set of age-group-by-arthritis interaction terms were non-significant and suggest that the arthritis effect remains constant across the age-groups. Similar to unadjusted models (Table 2), for individuals reporting 
Table 1 Characteristics of adults with and without self-reported arthritis

\begin{tabular}{|c|c|c|c|c|c|c|}
\hline & \multicolumn{2}{|c|}{ Arthritis } & \multicolumn{2}{|c|}{ No arthritis } & \multirow[t]{2}{*}{ Total } & \multirow[t]{2}{*}{$P$-value } \\
\hline & $N$ & Weighted (\%) & $N$ & Weighted (\%) & & \\
\hline \multicolumn{7}{|l|}{ Sex } \\
\hline Male & 555 & 43.4 & 1,083 & 48.8 & 1,638 & \multirow[t]{3}{*}{0.0579} \\
\hline Female & 1,002 & 56.6 & 1,199 & 51.2 & 2,201 & \\
\hline Total & 1,557 & & 2,282 & & 3,839 & \\
\hline \multicolumn{7}{|l|}{ Age category } \\
\hline $35-44$ & 107 & 15.5 & 535 & 39.0 & 642 & \multirow[t]{6}{*}{$<.0001$} \\
\hline $45-54$ & 226 & 18.3 & 600 & 26.3 & 826 & \\
\hline $55-64$ & 297 & 25.3 & 387 & 17.5 & 684 & \\
\hline $65-74$ & 507 & 22.1 & 457 & 10.5 & 964 & \\
\hline $75-89$ & 420 & 18.7 & 303 & 6.7 & 723 & \\
\hline Total & 1,557 & & 2,282 & & 3,839 & \\
\hline \multicolumn{7}{|l|}{ Race category } \\
\hline White & 1,038 & 84.3 & 1,520 & 80.6 & 2,558 & \multirow[t]{4}{*}{0.0924} \\
\hline Black & 458 & 10.1 & 628 & 10.8 & 1,086 & \\
\hline Other races & 58 & 5.7 & 119 & 8.5 & 177 & \\
\hline Total & 1,554 & & 2,267 & & 3,821 & \\
\hline \multicolumn{7}{|l|}{ Income category } \\
\hline$<\$ 20,000$ & 436 & 17.5 & 345 & 8.2 & 781 & \multirow[t]{5}{*}{$<.0001$} \\
\hline$\$ 20,000-\$ 34,999$ & 308 & 20.1 & 390 & 13.5 & 698 & \\
\hline$\$ 35,000-\$ 74,999$ & 437 & 35.6 & 737 & 36.6 & 1,174 & \\
\hline$\$ 75,000^{+}$ & 225 & 26.8 & 636 & 41.8 & 861 & \\
\hline Total & 1,406 & & 2,108 & & 3,514 & \\
\hline \multicolumn{7}{|l|}{ Education } \\
\hline$<$ High school & 264 & 11.6 & 200 & 6.8 & 464 & \multirow[t]{5}{*}{$<.0001$} \\
\hline High school & 513 & 30.6 & 643 & 27.2 & 1,156 & \\
\hline Some post-high school & 345 & 25.4 & 510 & 20.7 & 855 & \\
\hline 4-year college degree or higher & 426 & 32.3 & 915 & 45.3 & 1,341 & \\
\hline Total & 1,548 & & 2,268 & & 3,816 & \\
\hline \multicolumn{7}{|l|}{ Body mass index category } \\
\hline$<18.5$ & 14 & 0.8 & 29 & 1.7 & 43 & \multirow[t]{5}{*}{$<.0001$} \\
\hline $18.5-25$ & 307 & 22.9 & 650 & 34.8 & 957 & \\
\hline $25-30$ & 485 & 38.2 & 784 & 36.5 & 1,269 & \\
\hline$>30$ & 598 & 38.2 & 570 & 27.0 & 1,168 & \\
\hline Total & 1,404 & & 2,033 & & 3,437 & \\
\hline \multicolumn{7}{|l|}{ Coronary heart disease } \\
\hline Yes & 294 & 16.3 & 189 & 6.0 & 483 & \multirow[t]{3}{*}{$<.0001$} \\
\hline No & 1,253 & 83.8 & 2,092 & 94.0 & 3,345 & \\
\hline Total & 1,547 & & 2,281 & & 3,828 & \\
\hline \multicolumn{7}{|l|}{ Stroke } \\
\hline Yes & 135 & 7.7 & 87 & 2.1 & 222 & \multirow[t]{3}{*}{$<.0001$} \\
\hline No & 1,419 & 92.3 & 2,195 & 97.9 & 3,614 & \\
\hline Total & 1,554 & & 2,282 & & 3,836 & \\
\hline \multicolumn{7}{|l|}{ Diabetes mellitus } \\
\hline Yes & 413 & 17.7 & 313 & 9.8 & 726 & $<.0,001$ \\
\hline No & 1,143 & 82.3 & 1,968 & 90.2 & 3,111 & \\
\hline Total & 1,556 & & 2,281 & & 3,837 & \\
\hline Sleep disorder & & & & & & \\
\hline
\end{tabular}


Table 1 continued

\begin{tabular}{|c|c|c|c|c|c|c|}
\hline & \multicolumn{2}{|c|}{ Arthritis } & \multicolumn{2}{|c|}{ No arthritis } & \multirow[t]{2}{*}{ Total } & \multirow[t]{2}{*}{$P$-value } \\
\hline & $N$ & Weighted (\%) & $N$ & Weighted $(\%)$ & & \\
\hline Yes & 235 & 15.2 & 121 & 4.7 & 356 & $<.0001$ \\
\hline No & 1,320 & 84.8 & 2,158 & 95.3 & 3,478 & \\
\hline Total & 1,555 & & 2,279 & & 3,834 & \\
\hline \multicolumn{7}{|c|}{ Respiratory problems } \\
\hline Yes & 376 & 21.6 & 268 & 9.3 & 644 & $<.0001$ \\
\hline No & 1,180 & 78.4 & 2,014 & 90.7 & 3,194 & \\
\hline Total & 1,556 & & 2,282 & & 3,838 & \\
\hline \multicolumn{7}{|c|}{ Depression } \\
\hline Yes & 303 & 20.9 & 256 & 12.1 & 559 & 0.0001 \\
\hline No & 1,252 & 79.1 & 2,025 & 87.9 & 3,277 & \\
\hline Total & 1,555 & & 2,281 & & 3,836 & \\
\hline
\end{tabular}

arthritis, the HRQOL scores were highest for EQ-5D and lowest for QWB-SA for all age-groups. In general, the HRQOL scores declined from 35- to 64-year age-groups and then showed a "bump up" in the 65-74-year age-group for both arthritis and non-arthritis groups.

\section{Discussion}

Using a large nationally representative population-based survey, we show that adults with self-reported arthritis have lower HRQOL scores than adults who did not report arthritis after adjusting for age and sex and even after adjusting for several covariates. This was seen across the six HRQOL instruments. In addition, our study provides important national age-related reference averages for six HRQOL indexes for adults with self-reported arthritis that can be used in future decision and cost-effectiveness analyses.

Arthritis is very common in age groups 35-89 years and a major contributor to HRQOL in the US population. The prevalence of arthritis has been steadily increasing $[1,36]$. We found a $31 \%$ prevalence of self-reported arthritis by the NHMS study. Previous surveys that differ in age-groups targeted and how arthritis was defined have shown similar prevalence. In the Medical Expenditures Panel Survey Household Component (MEPS-HC; computer-assisted personal interviewing), the prevalence of arthritis in 35-89 age-group was 30\% in 2003 [37] (Table 3). In two other national representative surveys, the US Valuation of the EuroQol EQ-5D Health States Survey in 2002 (USVEQ; self-administered with interviewer present) [24] and Joint Canada/United States Survey of Health from 2002 to 2003 (JCUSH; telephone survey) [38], the prevalence of self-reported arthritis for ages 35-89 was consistently estimated at around $30 \%$ (Table 3 ).

One of our interesting results is the declining HRQOL scores in the 35-64 age-group seen in both arthritis and non-arthritis groups and then a trend toward an improvement in their HRQOL in the 65-74-year age-group. This interesting finding was also reported for the whole cohort in the original publication from the NHMS [23]. Fryback et al. suggest that this may relate to reporting bias of poor HRQOL in 55-64 age-group (baby boomers) or greater HRQOL in 65-74 age-group (recent retirees). Another potential reason may be selective non-participation in the survey by age and health around retirement age. Perhaps, more healthy people in the 55-64 age-group may be too busy, or perhaps, less healthy people in the 65-74 group may be too ill to participate.

Our data have important implications for public policy. First, our analysis provides age-related HRQOL scores for six commonly used measures that can be used in future decision and cost-effectiveness analyses. The US Public Health Service Panel on Cost-Effectiveness in Health and Medicine [39] recommended using HRQOL scores based on preference weights derived from the general public, rather than from patients, for cost-effectiveness analyses. The indexes used here meet this requirement. We provide population-based estimates of HRQOL burden for each age-group-by-arthritis stratum. Second, previous studies have found that the minimally important difference in HRQOL preference-based scores - the smallest difference in scores that patients perceive as beneficial [40] - is about 0.03 , with a range from 0.01 to 0.10 [41-43]. The differences in HRQOL scores between arthritis and non-arthritis groups in our study exceed the minimally important difference and are thus clinically meaningful. Third, as previously reported, each of the six HRQOL measures provides different scores associated with the impact of arthritis, thus choice of measure can affect estimates of quality-adjusted life years (QALYs) gained by an intervention and thus different incremental cost-effectiveness estimates. In an analysis of treatment of rheumatoid arthritis with combination of infliximab and methotrexate versus 
Table 2 Unadjusted mean (SE) HRQOL index score of US adults aged 35-89 by gender, age, and arthritis

\begin{tabular}{|c|c|c|c|c|c|c|}
\hline \multirow[t]{2}{*}{ Index } & \multicolumn{2}{|c|}{ Whole group } & \multicolumn{2}{|l|}{ Men } & \multicolumn{2}{|l|}{ Women } \\
\hline & Arthritis & No arthritis & Arthritis & No arthritis & Arthritis & No arthritis \\
\hline \multicolumn{7}{|l|}{ EQ-5D } \\
\hline $35-44$ & $0.77(0.03)$ & $0.91(0.01)$ & $0.78(0.06)$ & $0.92(0.01)$ & $0.77(0.03)$ & $0.91(0.01)$ \\
\hline $45-54$ & $0.78(0.02)$ & $0.91(0.01)$ & $0.78(0.02)$ & $0.91(0.01)$ & $0.78(0.03)$ & $0.90(0.01)$ \\
\hline $55-64$ & $0.77(0.01)$ & $0.90(0.01)$ & $0.78(0.02)$ & $0.90(0.01)$ & $0.76(0.02)$ & $0.90(0.01)$ \\
\hline $65-74$ & $0.80(0.01)$ & $0.91(0.01)$ & $0.82(0.02)$ & $0.90(0.01)$ & $0.79(0.01)$ & $0.91(0.01)$ \\
\hline $75-89$ & $0.80(0.01)$ & $0.89(0.01)$ & $0.82(0.01)$ & $0.89(0.01)$ & $0.77(0.01)$ & $0.89(0.01)$ \\
\hline \multicolumn{7}{|l|}{ HALex } \\
\hline $35-44$ & $0.75(0.03)$ & $0.86(0.01)$ & $0.74(0.04)$ & $0.87(0.01)$ & $0.75(0.04)$ & $0.86(0.01)$ \\
\hline $45-54$ & $0.71(0.03)$ & $0.85(0.01)$ & $0.74(0.03)$ & $0.83(0.01)$ & $0.69(0.04)$ & $0.86(0.01)$ \\
\hline $55-64$ & $0.68(0.03)$ & $0.81(0.02)$ & $0.68(0.03)$ & $0.81(0.02)$ & $0.68(0.04)$ & $0.81(0.03)$ \\
\hline $65-74$ & $0.68(0.02)$ & $0.82(0.01)$ & $0.70(0.02)$ & $0.82(0.02)$ & $0.67(0.02)$ & $0.81(0.02)$ \\
\hline $75-89$ & $0.68(0.02)$ & $0.80(0.01)$ & $0.71(0.03)$ & $0.80(0.02)$ & $0.64(0.03)$ & $0.81(0.02)$ \\
\hline \multicolumn{7}{|l|}{ HUI2 } \\
\hline $35-44$ & $0.74(0.03)$ & $0.88(0.01)$ & $0.72(0.06)$ & $0.91(0.01)$ & $0.75(0.03)$ & $0.87(0.01)$ \\
\hline $45-54$ & $0.77(0.02)$ & $0.88(0.01)$ & $0.75(0.04)$ & $0.89(0.01)$ & $0.78(0.03)$ & $0.87(0.01)$ \\
\hline $55-64$ & $0.76(0.02)$ & $0.87(0.01)$ & $0.78(0.03)$ & $0.86(0.01)$ & $0.74(0.03)$ & $0.87(0.01)$ \\
\hline $65-74$ & $0.79(0.01)$ & $0.89(0.01)$ & $0.81(0.02)$ & $0.89(0.01)$ & $0.79(0.02)$ & $0.89(0.02)$ \\
\hline $75-89$ & $0.78(0.01)$ & $0.88(0.01)$ & $0.80(0.01)$ & $0.88(0.02)$ & $0.77(0.02)$ & $0.88(0.01)$ \\
\hline \multicolumn{7}{|l|}{ HUI3 } \\
\hline $35-44$ & $0.64(0.05)$ & $0.85(0.01)$ & $0.62(0.09)$ & $0.89(0.02)$ & $0.64(0.06)$ & $0.84(0.02)$ \\
\hline $45-54$ & $0.71(0.03)$ & $0.86(0.01)$ & $0.7(0.05)$ & $0.87(0.01)$ & $0.72(0.04)$ & $0.86(0.01)$ \\
\hline $55-64$ & $0.68(0.03)$ & $0.84(0.01)$ & $0.71(0.04)$ & $0.82(0.02)$ & $0.67(0.05)$ & $0.86(0.02)$ \\
\hline $65-74$ & $0.73(0.02)$ & $0.86(0.02)$ & $0.75(0.03)$ & $0.85(0.02)$ & $0.72(0.03)$ & $0.87(0.02)$ \\
\hline $75-89$ & $0.69(0.02)$ & $0.83(0.02)$ & $0.71(0.03)$ & $0.83(0.03)$ & $0.67(0.03)$ & $0.84(0.02)$ \\
\hline \multicolumn{7}{|l|}{ QWB-SA } \\
\hline $35-44$ & $0.59(0.03)$ & $0.71(0.01)$ & $0.60(0.04)$ & $0.74(0.01)$ & $0.58(0.03)$ & $0.69(0.01)$ \\
\hline $45-54$ & $0.59(0.02)$ & $0.7(0.01)$ & $0.58(0.02)$ & $0.71(0.01)$ & $0.59(0.02)$ & $0.68(0.01)$ \\
\hline $55-64$ & $0.58(0.02)$ & $0.68(0.01)$ & $0.62(0.02)$ & $0.69(0.01)$ & $0.55(0.02)$ & $0.67(0.01)$ \\
\hline $65-74$ & $0.59(0.01)$ & $0.68(0.01)$ & $0.06(0.01)$ & $0.67(0.01)$ & $0.58(0.01)$ & $0.69(0.02)$ \\
\hline $75-89$ & $0.56(0.01)$ & $0.66(0.01)$ & $0.57(0.02)$ & $0.64(0.02)$ & $0.55(0.01)$ & $0.69(0.02)$ \\
\hline \multicolumn{7}{|l|}{ SF-6D } \\
\hline $35-44$ & $0.74(0.02)$ & $0.81(0.01)$ & $0.74(0.04)$ & $0.82(0.01)$ & $0.74(0.03)$ & $0.81(0.01)$ \\
\hline $45-54$ & $0.74(0.02)$ & $0.82(0.01)$ & $0.76(0.02)$ & $0.82(0.01)$ & $0.73(0.02)$ & $0.81(0.01)$ \\
\hline $55-64$ & $0.72(0.01)$ & $0.82(0.01)$ & $0.73(0.02)$ & $0.82(0.01)$ & $0.71(0.02)$ & $0.81(0.01)$ \\
\hline $65-74$ & $0.73(0.01)$ & $0.83(0.01)$ & $0.75(0.01)$ & $0.83(0.01)$ & $0.72(0.01)$ & $0.82(0.02)$ \\
\hline $75-89$ & $0.71(0.01)$ & $0.82(0.01)$ & $0.73(0.01)$ & $0.81(0.01)$ & $0.69(0.01)$ & $0.82(0.02)$ \\
\hline
\end{tabular}

methotrexate alone, Marra et al. [44] showed that the four HRQOL measures (EQ-5D, HUI2, HUI3, and SF-6D) provided different QALYs and therefore different incremental cost-effectiveness scores. In their analysis, HUI3 produced the largest incremental QALYs gain followed by EQ-5D, HUI2, and SF-6D. It may be necessary for analysts doing costeffectiveness analyses to agree upon a common measure of HRQOL in order to standardize analytic results.

Our survey is not without limitations. NHMS was administered using a random digital dial telephone survey, which may have had somewhat higher response rates among people who are more educated and/or with higher household incomes compared with US Census figures for the year 2000. Thus, the NHMS may have reached somewhat more healthy persons [23]. Although the question eliciting arthritis diagnosis has been widely used in similar surveys, cases were not verified by examination or medical records. People responding to telephone surveys tend to report slightly better health than those responding to self-administered, paper, and pencil questionnaires [45]. Telephone-based health surveys 

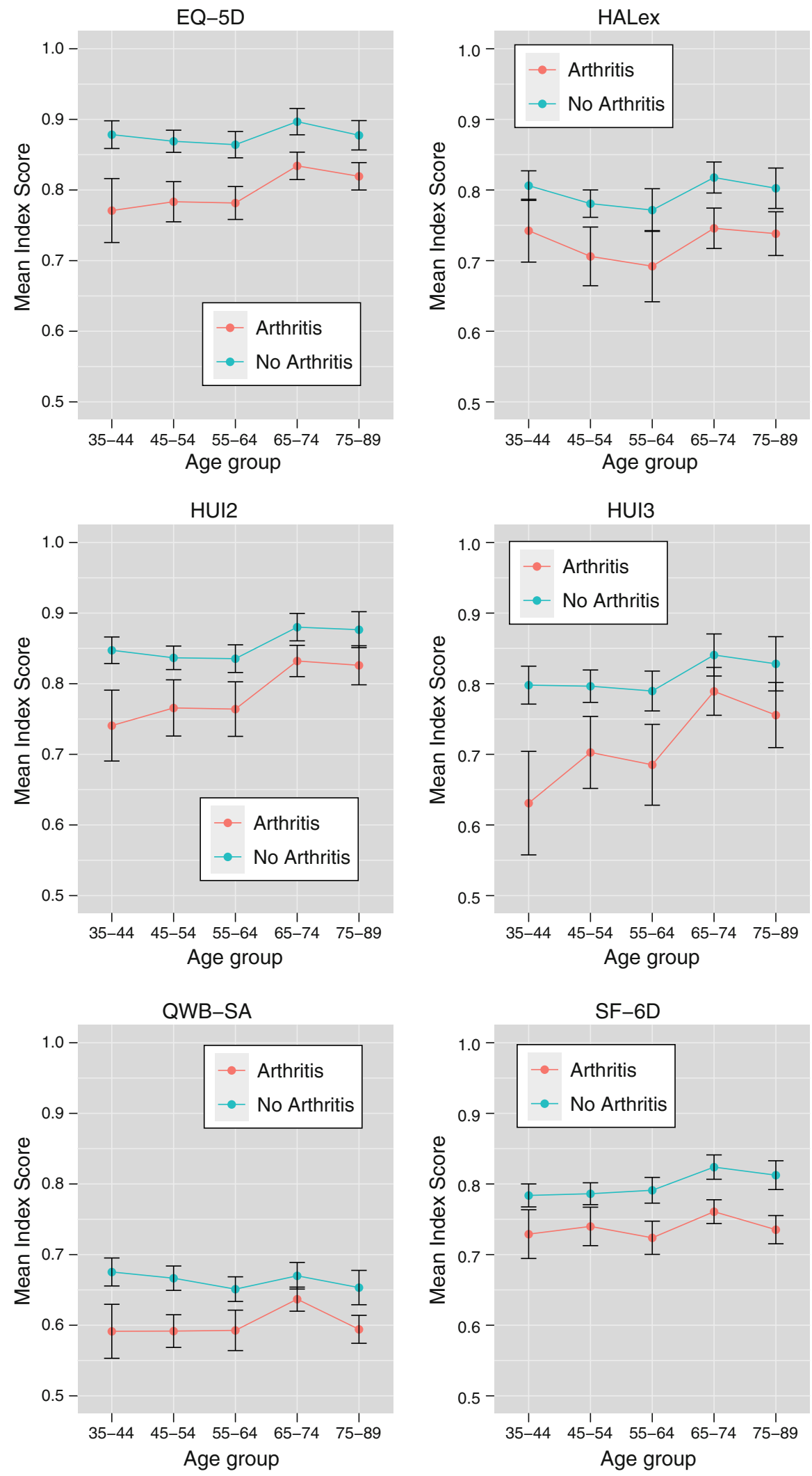

Fig. 1 Means (SE) estimating non-institutionalized US population health-related quality-of-life (HRQOL) by age are shown for selfreported arthritis and no arthritis using 6 standardized indexes. The mean estimates are adjusted for gender, race, level of education,

annual household income body mass index, and the presence or absence of the following self-reported health care professionaldiagnosed comorbidities: coronary heart disease, diabetes, stroke, COPD, and sleeping disorder 
Table 3 Arthritis in four nationally representative data sets for ages 35-89

\begin{tabular}{|c|c|c|c|c|c|}
\hline & \multicolumn{2}{|l|}{ Arthritis } & \multicolumn{2}{|l|}{ No arthritis } & \multirow[t]{2}{*}{ Arthritis question asked } \\
\hline & $\begin{array}{l}\text { Unweighted } \\
N\end{array}$ & $\begin{array}{l}\text { Weighted } \\
\%\end{array}$ & $\begin{array}{l}\text { Unweighted } \\
N\end{array}$ & $\begin{array}{l}\text { Weighted } \\
\%\end{array}$ & \\
\hline NHMS & 1,557 & 31.3 & 2,282 & 68.7 & $\begin{array}{l}\text { Have you ever been told (by a doctor or other health professional) that } \\
\text { you had arthritis? }\end{array}$ \\
\hline $\begin{array}{l}\text { MEPS* (proxy } \\
\text { included) }\end{array}$ & 4,253 & 30.0 & 9,728 & 70.0 & $\begin{array}{l}\text { (Have/Has) (PERSON) ever been told by a doctor or other health } \\
\text { professional that (PERSON) had arthritis? }\end{array}$ \\
\hline (non-proxy only) & 4,225 & 29.9 & 9,699 & 70.1 & \\
\hline USVEQ & 693 & 30.1 & 1,704 & 69.9 & $\begin{array}{l}\text { Please read this card and tell me if you have ever been told by a health } \\
\text { professional that you have any of the following conditions: Arthritis }\end{array}$ \\
\hline $\begin{array}{l}\text { JCUSH (proxy } \\
\text { included) }\end{array}$ & 1,104 & 25.2 & 2,804 & 74.8 & $\begin{array}{l}\text { Have you ever been told by a doctor or other health professional that } \\
\text { you have arthritis, not including fibromyalgia? }\end{array}$ \\
\hline $\begin{array}{l}\text { (non-proxy only) } \\
\text { [US respondents } \\
\text { only] }\end{array}$ & 1,065 & 25.1 & 2,728 & 74.9 & \\
\hline
\end{tabular}

NHMS National Health Measurement Study, MEPS Medical Expenditures Panel Survey, USVEQ US Valuation of the EuroQol EQ-5D Health States Survey, JCUSH Joint Canada/United States Survey of Health

* All estimates were generated within the 35-89 age-group using study-specific survey weights except for MEPS which surveys ages 18-90 top coding all ages $>85$ as " 85 " for confidentiality purposes. So the MEPS survey-weighted estimates represent ages 35-90

were apparently little affected by cell phone usage in the timeframe of the NHMS [46].

In conclusion, this study provides important national reference averages for six HRQOL indexes for adults with self-reported arthritis for future decision analysis and costeffectiveness analysis.

Acknowledgments NHMS was supported by grant P01-AG020679 from the National Institute on Aging. Dr. Khanna was supported by National Institutes of Health Awards (NIAMS K23 AR053858-04 and U01 UAR057936A). Ron D. Hays was supported in part by the UCLA Resource Center for Minority Aging Research/Center for Health Improvement in Minority Elderly (NIA P30AG021684) and by the UCLA/Drew Project EXPORT, (NCMHD 2P20MD000182). Dr Cherepanov was supported by a grant (T32 HS000046) to University of California, Los Angeles, and RAND Corporation, Santa Monica, from the Agency for Healthcare Research and Quality.

Open Access This article is distributed under the terms of the Creative Commons Attribution Noncommercial License which permits any noncommercial use, distribution, and reproduction in any medium, provided the original author(s) and source are credited.

\section{Appendix}

See Table 4.

Table 4 Mean (SE) HRQOL index score of US adults aged 35-89 by gender, age, and arthritis

\begin{tabular}{lll}
\hline Index & Arthritis & No arthritis \\
\hline $\begin{array}{l}\text { EQ-5D } \\
35-44\end{array}$ & $0.77(0.02)$ & $0.88(0.01)$ \\
\hline
\end{tabular}

Table 4 continued

\begin{tabular}{|c|c|c|}
\hline Index & Arthritis & No arthritis \\
\hline $45-54$ & $0.78(0.01)$ & $0.87(0.01)$ \\
\hline $55-64$ & $0.78(0.01)$ & $0.86(0.01)$ \\
\hline $65-74$ & $0.83(0.01)$ & $0.90(0.01)$ \\
\hline $75-89$ & $0.82(0.01)$ & $0.88(0.01)$ \\
\hline \multicolumn{3}{|l|}{ HALex } \\
\hline $35-44$ & $0.74(0.02)$ & $0.81(0.01)$ \\
\hline $45-54$ & $0.71(0.02)$ & $0.78(0.01)$ \\
\hline $55-64$ & $0.69(0.03)$ & $0.77(0.02)$ \\
\hline $65-74$ & $0.75(0.01)$ & $0.82(0.01)$ \\
\hline $75-89$ & $0.74(0.02)$ & $0.80(0.01)$ \\
\hline \multicolumn{3}{|l|}{ HUI2 } \\
\hline $35-44$ & $0.74(0.03)$ & $0.85(0.01)$ \\
\hline $45-54$ & $0.77(0.02)$ & $0.84(0.01)$ \\
\hline $55-64$ & $0.76(0.02)$ & $0.84(0.01)$ \\
\hline $65-74$ & $0.83(0.01)$ & $0.88(0.01)$ \\
\hline $75-89$ & $0.83(0.01)$ & $0.88(0.01)$ \\
\hline \multicolumn{3}{|l|}{ HUI3 } \\
\hline $35-44$ & $0.63(0.04)$ & $0.8(0.01)$ \\
\hline $45-54$ & $0.7(0.03)$ & $0.8(0.01)$ \\
\hline $55-64$ & $0.69(0.03)$ & $0.79(0.01)$ \\
\hline $65-74$ & $0.79(0.02)$ & $0.84(0.02)$ \\
\hline $75-89$ & $0.76(0.02)$ & $0.83(0.02)$ \\
\hline \multicolumn{3}{|c|}{ QWB-SA } \\
\hline $35-44$ & $0.59(0.02)$ & $0.68(0.01)$ \\
\hline $45-54$ & $0.59(0.01)$ & $0.67(0.01)$ \\
\hline $55-64$ & $0.59(0.01)$ & $0.65(0.01)$ \\
\hline $65-74$ & $0.64(0.01)$ & $0.67(0.01)$ \\
\hline
\end{tabular}


Table 4 continued

\begin{tabular}{clc}
\hline Index & Arthritis & No arthritis \\
\hline $75-89$ & $0.59(0.01)$ & $0.65(0.01)$ \\
SF-6D & & \\
$35-44$ & $0.73(0.02)$ & $0.78(0.01)$ \\
$45-54$ & $0.74(0.01)$ & $0.79(0.01)$ \\
$55-64$ & $0.72(0.01)$ & $0.79(0.01)$ \\
$65-74$ & $0.76(0.01)$ & $0.82(0.01)$ \\
$75-89$ & $0.74(0.01)$ & $0.81(0.01)$ \\
\hline
\end{tabular}

The mean estimates are adjusted for gender, race, level of education, annual household income, body mass index, and the presence or absence of the following self-reported health care professional-diagnosed comorbidities: coronary heart disease, diabetes, stroke, COPD, and sleeping disorder

\section{References}

1. Helmick, C. G., Felson, D. T., Lawrence, R. C., Gabriel, S., Hirsch, R., Kwoh, C. K., et al. (2008). Estimates of the prevalence of arthritis and other rheumatic conditions in the United States. Part I. Arthritis and Rheumatism, 58(1), 15-25.

2. Mili, F., Helmick, C. G., \& Moriarty, D. G. (2003). Health related quality of life among adults reporting arthritis: Analysis of data from the Behavioral Risk Factor Surveillance System, US, 1996-99. Journal of Rheumatology, 30(1), 160-166.

3. Khanna, D., \& Tsevat, J. (2007). Health-related quality of life-an introduction. American Journal of Managed Care, 13(Suppl 9), S218-S223.

4. McDowell, I. (2006). Measuring health: A guide or rating scales and questionnaires (3rd ed.). New York: Oxford University Press.

5. Meenan, R. F. (1982). The AIMS approach to health status measurement: Conceptual background and measurement properties. Journal of Rheumatology, 9(5), 785-788.

6. Meenan, R. F., Mason, J. H., Anderson, J. J., Guccione, A. A., \& Kazis, L. E. (1992). AIMS2. The content and properties of a revised and expanded Arthritis Impact Measurement Scales Health Status Questionnaire. Arthritis and Rheumatism, 35(1), 1-10.

7. Fries, J. F., Spitz, P., Kraines, R. G., \& Holman, H. R. (1980). Measurement of patient outcome in arthritis. Arthritis and Rheumatism, 23(2), 137-145.

8. Zahran, H., Kobau, R., Moriarty, D. G., Zack, M. M., Holt, J., \& Donehoo, R. (2005). Health-Related Quality of Life Surveillance-United States. MMWR Morbidity and mortality weekly report, 54(SS04), 1-35.

9. Bolen, J., Helmick, C. G., \& Sacks, J. J. (2002). Prevalence of self-reported arthritis or chronic joint symptoms among adultsUnited States, 2001. MMWR Morbidity and Mortality Weekly Report, 51(42), 948-950.

10. Centers for Disease Control, Prevention (CDC). (2006). State prevalence of self-reported doctor-diagnosed arthritis and arthritis-attributable activity limitation-United States, 2003. MMWR Morbidity and Mortality Weekly Report, 55(17), 477-481.

11. Schneider, S., Schmitt, G., \& Richter, W. (2006). Prevalence and correlates of inflammatory arthritis in Germany: Data from the First National Health Survey. Rheumatology International, 27(1), 29-38.

12. Hootman, J., Bolen, J., \& Helmick, C. (2006). Prevalence of doctor-diagnosed arthritis and arthritis-attributable activity
limitation-United States, 2003-2005. MMWR Morbidity and Mortality Weekly Report, 55(40), 1089-1092.

13. Lima, M. G., Barros, M. B., Cesar, C. L., Goldbaum, M., Carandina, L., \& Ciconelli, R. M. (2009). Impact of chronic disease on quality of life among the elderly in the state of Sao Paulo, Brazil: A population-based study. Revista Panamericana de Salud Pública, 25(4), 314-321.

14. Badley, E. M., \& Ansari, H. (2010). Arthritis and arthritisattributable activity limitations in the United States and Canada: A cross-border comparison. Arthritis Care \& Research (Hoboken), 62(3), 308-315.

15. Anderson, J. P., Kaplan, R. M., \& Ake, C. (2004). Arthritis impact on U.S. life quality: Morbidity and mortality effects from National Health Interview Survey Data 1986-1988 and 1994 using QWB estimates of well-being. Social Indicators Research, 69(1), 67-91.

16. Hanmer, J., Lawrence, W. F., Anderson, J. P., Kaplan, R. M., \& Fryback, D. G. (2006). Report of nationally representative values for the noninstitutionalized US adult population for 7 health-related quality-of-life scores. Medical Decision Making, 26(4), 391-400.

17. Brazier, J., Roberts, J., Tsuchiya, A., \& Busschbach, J. (2004). A comparison of the EQ-5D and SF-6D across seven patient groups. Health Economics, 13(9), 873-884.

18. Kaplan, R. M., Alcaraz, J. E., Anderson, J. P., \& Weisman, M. (1996). Quality-adjusted life years lost to arthritis: Effects of gender, race, and social class. Arthritis Care \& Research, 9(6), 473-482.

19. Mo, F., Choi, B. C., Li, F. C., \& Merrick, J. (2004). Using Health Utility Index (HUI) for measuring the impact on health-related quality of Life (HRQL) among individuals with chronic diseases. ScientificWorld Journal, 4, 746-757.

20. Kopec, J. A., Williams, J. I., To, T., \& Austin, P. C. (2000). Measuring population health: correlates of the Health Utilities Index among English and French Canadians. Canadian Journal of Public Health, 91(6), 465-470.

21. Yabroff, K. R., McNeel, T. S., Waldron, W. R., Davis, W. W., Brown, M. L., Clauser, S., et al. (2007). Health limitations and quality of life associated with cancer and other chronic diseases by phase of care. Medical Care, 45(7), 629-637.

22. Ko, Y., \& Coons, S. J. (2006). Self-reported chronic conditions and EQ-5D index scores in the US adult population. Current Medical Research and Opinion, 22(10), 2065-2071.

23. Fryback, D. G., Dunham, N. C., Palta, M., Hanmer, J., Buechner, J., Cherepanov, D., et al. (2007). US norms for six generic healthrelated quality-of-life indexes from the National Health Measurement study. Medical Care, 45(12), 1162-1170.

24. Shaw, J. W., Johnson, J. A., \& Coons, S. J. (2005). US valuation of the EQ-5D health states: development and testing of the D1 valuation model. Medical Care, 43(3), 203-220.

25. Feeney, D., Torrance, G., \& Furlong, W. (1996). Health utilities index. In B. Spilker (Ed.), Quality of life and pharmacoeconomics in clinical trials. Philadelphia, PA: Lippincott-Raven Press.

26. Feeny, D., Furlong, W., Torrance, G. W., Goldsmith, C. H., Zhu, Z., DePauw, S., et al. (2002). Multiattribute and single-attribute utility functions for the health utilities index mark 3 system. Medical Care, 40(2), 113-128.

27. Brazier, J., Roberts, J., \& Deverill, M. (2002). The estimation of a preference-based measure of health from the SF-36. Journal of Health Economics, 21(2), 271-292.

28. Kaplan, R. M., Sieber, W. J., \& Ganiats, T. G. (1997). The Quality of Well-Being Scale: Comparison of the intervieweradministered version with a self-administered questionnaire. Psychology \& Health, 12, 783-791.

29. Erickson, P. (1998). Evaluation of a population-based measure of quality of life: The Health and Activity Limitation Index (HALex). Quality of Life Research, 7(2), 101-114. 
30. Czaja, R., Blair, J., \& Sebestik, J. P. (1982). Respondent selection in a telephone survey: A comparison of three techniques. Journal of Marketing Research, 19, 381-385.

31. Mili, F., Helmick, C. G., \& Zack, M. M. (2002). Prevalence of arthritis: Analysis of data from the US Behavioral Risk Factor Surveillance System, 1996-99. The Journal of rheumatology, 29(9), 1981-1988.

32. Bombard, J. M., Powell, K. E., Martin, L. M., Helmick, C. G., \& Wilson, W. H. (2005). Validity and reliability of self-reported arthritis: Georgia senior centers, 2000-2001. American Journal of Preventive Medicine, 28(3), 251-258.

33. Sacks, J. J., Harrold, L. R., Helmick, C. G., Gurwitz, J. H., Emani, S., \& Yood, R. A. (2005). Validation of a surveillance case definition for arthritis. The Journal of Rheumatology, 32(2), 340-347.

34. Johnson, J. A., Coons, S. J., Ergo, A., \& Szava-Kovats, G. (1998). Valuation of EuroQOL (EQ-5D) health states in an adult US sample. Pharmacoeconomics, 13(4), 421-433.

35. Ware, J. E., Jr. (2000). SF-36 health survey update. Spine, 25(24), 3130-3139.

36. Lawrence, R. C., Helmick, C. G., Arnett, F. C., Deyo, R. A., Felson, D. T., Giannini, E. H., et al. (1998). Estimates of the prevalence of arthritis and selected musculoskeletal disorders in the United States. Arthritis \& Rheumatology, 41(5), 778-799.

37. Yelin, E., Murphy, L., Cisternas, M. G., Foreman, A. J., Pasta, D. J., \& Helmick, C. G. (2007). Medical care expenditures and earnings losses among persons with arthritis and other rheumatic conditions in 2003, and comparisons with 1997. Arthritis \& Rheumatology, 56(5), 1397-1407.

38. Sanmartin, C., Berthelot, J. M., Ng, E., Murphy, K., Blackwell, D. L., Gentleman, J. F., et al. (2006). Comparing health and health care use in Canada and the United States. Health Affairs (Millwood), 25(4), 1133-1142.
39. Weinstein, M. C., Siegel, J. E., Gold, M. R., Kamlet, M. S., \& Russell, L. B. (1996). Recommendations of the panel on costeffectiveness in health and medicine. JAMA, 276(15), 1253-1258.

40. Jaeschke, R., Singer, J., \& Guyatt, G. H. (1989). Measurement of health status. Ascertaining the minimal clinically important difference. Controlled Clinical Trials, 10(4), 407-415.

41. Walters, S. J., \& Brazier, J. E. (2005). Comparison of the minimally important difference for two health state utility measures: EQ-5D and SF-6D. Quality of Life Research, 14(6), 1523-1532.

42. Khanna, D., Furst, D. E., Wong, W. K., Tsevat, J., Clements, P. J., Park, G. S. et al. (2007). Reliability, validity, and minimally important differences of the SF-6D in systemic sclerosis. Quality of Life Research.

43. Marra, C. A., Woolcott, J. C., Kopec, J. A., Shojania, K., Offer, R., Brazier, J. E., et al. (2005). A comparison of generic, indirect utility measures (the HUI2, HUI3, SF-6D, and the EQ-5D) and disease-specific instruments (the RAQoL and the HAQ) in rheumatoid arthritis. Social Science and Medicine, 60(7), $1571-1582$.

44. Marra, C. A., Marion, S. A., Guh, D. P., Najafzadeh, M., Wolfe, F., Esdaile, J. M., et al. (2007). Not all "quality-adjusted life years" are equal. Journal of Clinical Epidemiology, 60(6), 616-624.

45. Hays, R. D., Kim, S., Spritzer, K., Kaplan, R. M., Tally, S., Feeny, D. et al. (2009). Effects of mode and order of administration on generic health-related quality of life scores. Value in Health (in press).

46. Blumberg, S. J., Luke, J. V., \& Cynamon, M. L. (2006). Telephone coverage and health survey estimates: Evaluating the need for concern about wireless substitution. American Journal of Public Health, 96(5), 926-931. 